\title{
Study on the Causes of Water Environmental Pollution of Important Rivers in Haihe River Basin and Countermeasures
}

\author{
$\mathrm{Xu} \mathrm{He} \mathrm{H}^{1, *}$, Hou Siyan ${ }^{1}$ \\ ${ }^{1}$ Water Resource Protection Research Institute of Haihe River Water Conservancy Commission, MWR
}

\begin{abstract}
The water quality of six important rivers in Haihe River Basin, including Yongding River, Luanhe River, North Canal, Daqing River, South Canal and Chaobai River, was evaluated. The influence of point source and non-point source on water quality was analyzed. The causes of water environmental pollution in the major rivers were preliminarily revealed. The results show that the water quality of Chaobai River is good, and the impact of point source and non-point source discharge on the water body is small. Other rivers are affected by different degrees of point source and non-point source pollution. Based on the analysis results, the engineering measures and management countermeasures for river regulation are put forward.
\end{abstract}

\section{Introduction}

The "Beijing Tianjin Hebei coordinated development planning outline" issued by the CPC Central Committee and the State Council clearly proposes to promote the governance of "Six Rivers" green ecological river corridor of Yongding River, Luanhe River, North Canal, Daqing River, South Canal and Chaobai River, and finish the "five lakes" ecological protection and restoration of Baiyangdian Lake, Hengshui Lake, Qilihai Lake, Nandagang Lake, Beidagang Lake. "Six rivers" and "five lakes" area covers the ecological core area of Beijing Tianjin Hebei. This area includes both water conservation area and ecological corridor connecting urban agglomeration. It also includes the protection of ecological diversity and biodiversity. The comprehensive management and ecological restoration of "six rivers and five lakes" is the focus of water environment and ecological protection and restoration in Haihe River Basin in the future.

This paper analyzes the water environment pollution of Yongding River, Luanhe River, North Canal, Daqing
River, South Canal and Chaobai River, and puts forward some countermeasures.

\section{Overview of the study area}

The Haihe River Basin $\left(35^{\circ} \mathrm{N} \sim 43^{\circ} \mathrm{N} 、 112^{\circ} \mathrm{E} \sim 120^{\circ} \mathrm{E}\right)$ is adjacent to the Bohai Sea in the East, the Taihang Mountains in the west, the Yellow River in the South and the Mongolian Plateau in the north. The river basin covers 8 provinces (autonomous regions and municipalities) including Beijing, Tianjin, Hebei, Shanxi, Henan, Shandong, Inner Mongolia and Liaoning, covering an area of $320600 \mathrm{~km}^{2}$, including Luanhe River, Haihe River and Tuhai Majia river system. Among them, Haihe River system includes Beisan River (Ji canal, Chaobai River and Beiyun canal), Yongding River, Daqing River, Ziya River, Heilonggang and Yundong area (Nanpai River, beipai River) and Zhangwei river system. Except Luanhe River, the other five rivers belong to Haihe River system. The North Canal and the south canal are also important parts of the Beijing Hangzhou Grand Canal, with a long history and culture. 


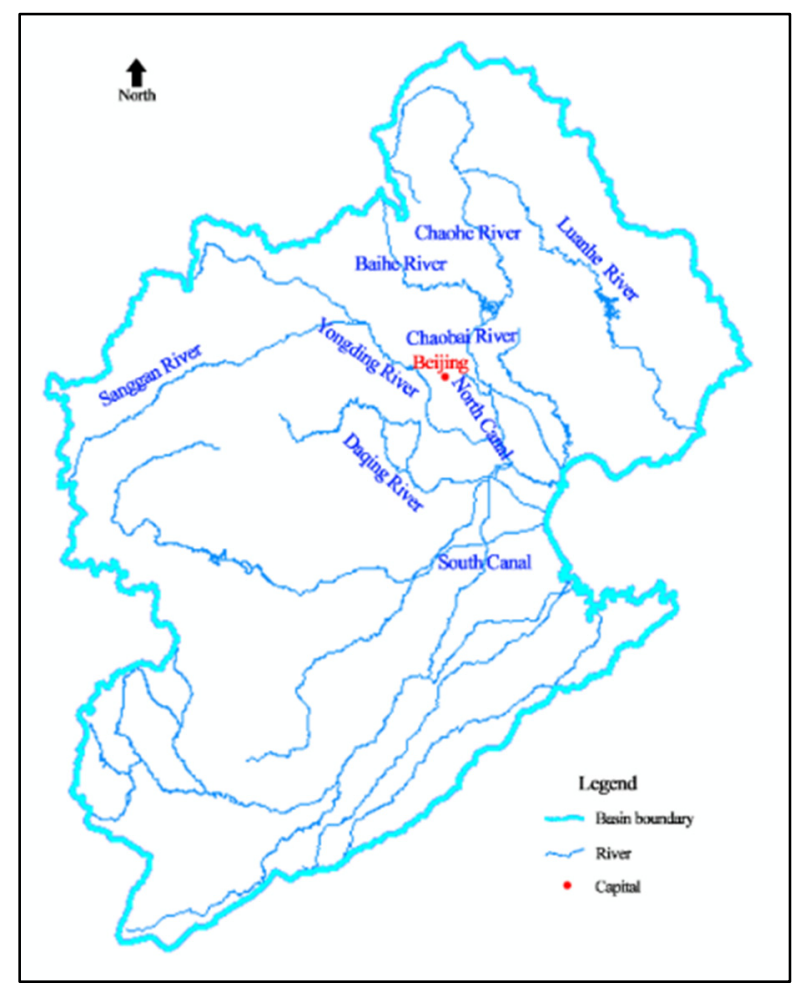

Figure1 Location Map of the Six Rivers

\section{Methods and data}

Based on the assessment of water environment status of major rivers in Haihe River Basin, the impact of point source and non-point source on river water quality was analyzed. The causes of water environmental pollution in the major rivers are preliminarily revealed.

\subsection{Assessment of river water environment}

Water quality type evaluation and water quality standard evaluation of important river water function areas in Haihe River Basin are carried out by river system. The current situation of water environment of each important river was analyzed.

The evaluation of water quality types in water function areas is based on the Environmental quality standard for surface water (GB3838-2002). The water quality of the water function area was evaluated by using the average value of the annual measured data (water temperature, total nitrogen, fecal coliform group were not included in the evaluation). The annual monitoring frequency method (only the mean method for the monitoring in March, June and October) is used to evaluate the water quality of the water functional area to meet the requirements.

\subsection{Analysis of water environmental pollution}

The main pollutants in Haihe River Basin are ammonia nitrogen, total phosphorus, chemical oxygen demand and permanganate index. The main pollution ways are the point source discharge of waste water from the sewage outlet into the river and the non-point source discharge of rural areas and soil erosion.

In order to further analyze the causes of pollution in important rivers, the first class A standard in the discharge standard of pollutants for urban sewage treatment plants (GB 18918-2002) was used to evaluate the COD and ammonia nitrogen of the sewage outlets. That is, the upper limit of COD emission concentration is $50 \mathrm{mg} / \mathrm{L}$ and ammonia nitrogen emission concentration is $5 \mathrm{mg} / \mathrm{L}$. The first grade standard of phosphate (based on P) in integrated wastewater discharge standard (GB8978-1996) is adopted as the discharge standard of total phosphorus. That is 5 $\mathrm{mg} / \mathrm{L}$ is the upper limit. The over standard discharge of sewage outlets into the river system was analyzed. The precipitation is concentrated in the flood season from June to September, and the non-point source is mostly washed into the river by precipitation in the flood season. And the point source emission is even throughout the year. Therefore, the influence of non-point source on the water quality of each river system is analyzed by analyzing the concentration difference of main pollution indexes in flood season and non flood season. If the water quality of the river becomes worse due to the increase of total nitrogen, total phosphorus, chemical oxygen demand and other indicators in flood season, it is considered that the river is affected by non-point source pollution. If the water quality of the river in non flood season is poor and the concentration of the main pollution index in non flood season decreases, the water quality of the river is mainly affected by the point source pollution of the sewage outlet.

\subsection{Data}

A total of 114 water function areas of six rivers and tributaries (including lakes and reservoirs) with a total 
length of $4902.9 \mathrm{~km}$ and an area of $981 \mathrm{~km}^{2}$ were screened out, The screening results of water related functional areas of each river are shown in Table 1. 29 water quality index data of important water function areas in Haihe River Basin from January to December 2018 were used for water quality assessment. The statistical analysis of point source emissions is based on the monitoring data of sewage outlets in Haihe River Basin from January to December in 2018. Among them, the flood season is from June to September, and the other months are non flood season.

\section{Results and analysis}

Overall, due to the influence of natural background, the fluoride concentration in Yongding River mountainous area is high, which affects the water quality. In addition, total phosphorus, chemical oxygen demand, ammonia nitrogen and permanganate index are the main pollutants in the river system. Water quality is affected by excessive discharge of pollutants from sewage outlet of the river, and water quality meeting standard rate in water functional area is low. Affected by non-point source pollution, total phosphorus concentration increases and water quality deteriorates further during flood season.

The water quality of Luanhe River system is good, and the standard rate of water function area is high. The water functional area with unqualified water quality is greatly affected by the discharge outlet of the river, especially the total phosphorus pollution concentration. The upstream mountainous area is obviously affected by non-point source pollution, and the concentration of pollutants in flood season increases as a whole, which has a certain impact on the water quality of individual water function areas.

According to the analysis of pollutant discharge and water quality change in flood season, the water quality of North Canal is affected by point source and non-point source. Because the North Canal mainly receives the Beijing Municipal Drainage and the tail water of the sewage treatment plant, there are many tributaries and branch ditches, and the discharge of excessive pollutants is large. In addition, the natural runoff is reduced, and the water quality is poor. These factors lead to the low annual water quality compliance rate of the river, among which ammonia nitrogen has the greatest impact. In flood season, the concentration of total phosphorus increased significantly, and the impact of non-point source discharge on water body intensified.

The water quality of Beiyishui, Zhongyishui, Beijuma, Baigou River, Xiaoqing River and some sections in the lower reaches of Daqing River are seriously polluted, and soil erosion still exists in the upstream mountainous areas. The water quality is influenced by the over discharge of pollutants and the non-point source at the discharge outlet of the river. Due to the large amount of point source discharge, high concentration of permanganate index and chemical oxygen demand, the water quality of 8 and 7 water function areas exceeded the standard, most of which were class V and inferior class v. Affected by the nonpoint source in flood season, the concentration increased further and the water pollution aggravated.
The South Canal is affected by both point source and non-point source. Ammonia nitrogen and chemical oxygen demand are mainly affected by the excessive discharge of sewage discharge outlet, which results in the water quality not meeting the standard. In flood season, affected by non-point source pollution, chemical oxygen demand and total phosphorus increased, and water quality further deteriorated.

On the whole, the water quality of Chaobai River is good, and the impact of point source and non-point source discharge on the water body is small.

\section{Countermeasures and suggestions}

\subsection{Project construction}

In the mountainous reach of Luanhe River, Chaobai River, Yongding River and Daqing River, the problems of insufficient water conservation and serious non-point source pollution are solved through water conservation forest construction and clean small watershed construction The regulation of gate and dam should be strengthened, and the goal of maintaining the base flow of the river will be achieved in the river section with good water source conditions.

On the basis of eliminating the hidden danger of flood control, the plain reaches of Luanhe River, Chaobai River, Yongding River and Daqing River, as well as the North Canal and south canal, focus on the construction of green ecological river corridor through the regulation of sewage outlets, the construction of ecological wetlands, the restoration of river water surface, and the ecological restoration of riparian zone. At the same time, urban river sections should be combined with the construction of water ecological civilization city, show waterfront culture, lay wetland parks along the river, maintain river and wetland landscape water surface, and create green ecological river landscape. The rural reach forms the ecological corridor of the country through the maintenance of the main channel water surface, the greening of the beach and the construction of the dike forest.

\subsection{Suggestions on management measures}

Explore a new investment model for comprehensive watershed management. Taking Yongding River Basin Investment Co., Ltd. as a sample, establish a river basin governance investment company with river basin as a unit and across provincial administrative regions. Drive the integration of river basin management with the integration of investors. Build a new mechanism of "investment, construction, management and transportation" with the government as the leading role, enterprises as the main body and market as the means. Form a Watershed Governance Model with the combination of government and market.

Explore a new investment model for watershed comprehensive management. Build a new mechanism of "investment, construction, management and transportation" with the government as the leading role, 
enterprises as the main body and market as the means. Form a watershed management mode combining government and market

Construct a water resources real time monitoring and scheduling system. Further improve the monitoring and early warning for drinking water source areas, important water function areas and other important objects. Speed up the use of cloud computing, Internet of things, big data, Internet plus and other information technology. The six rivers resources real-time monitoring and dispatching system is built around the business of ecological water quantity target supervision and assessment, ecological water quantity dispatching and management, water ecology evaluation, comprehensive treatment implementation effect evaluation, etc. Through resource integration, big data analysis model, virtual reality simulation and other technologies, it provides powerful supervision and management means. Master the water resources situation and changes in the basin in an all-round and multi-level way to improve the scientificity and accuracy of water resources dispatching.

\section{References}

1. FENG A P, WU C Q, WANG X L, et al. (2019) Spatial character analysis on nitrogen and phosphorus diffuse pollution in Haihe River Basin by remote sensing. China Environmental Science, 39(7): 2999-3008

2. BAI H B, LIU S M, YU S, et al. (2020) Spatialtemporal evolution characteristics of water quality in Haihe River Basin. Journal of Beijing Normal University (Natural Science), 56(2):290-297

3. Kong $\mathrm{P}$ R, Chen L D, Sun R H, Cheng X et al.(2018)Identification and optimized simulation of non-point source pollution risk patterns in the Haihe River Basin. Acta Ecologica Sinica, 38(12) :44454453

4. Guo S Y. (2018) Thoughts on improvement of water ecosystem in Haihe Basin. China Water Resources, $7: 4-7$ 